\title{
Impact of plasma irradiation on Tribolium castaneum
}

\author{
Waheed A. A. Sayed ${ }^{1} \cdot$ Reda S. Hassan ${ }^{1} \cdot$ Thanaa M. Sileem $^{1} \cdot$ Birgit A. Rumpold ${ }^{2} \mathbb{C}$
}

Received: 14 December 2020 / Revised: 9 March 2021 / Accepted: 11 March 2021 / Published online: 23 March 2021

(c) The Author(s) 2021

\begin{abstract}
Radio frequency plasma (RFP) could provide reliable, compact, cost-effective irradiation applications against insect pests of stored food and feed products. Sensitivity of red flour beetle Tribolium castaneum to RFP has been investigated using an irradiation applicator system with the two types of inert gases, argon (Ar) and helium (He), at $100 \mathrm{~W}$ for five exposure time levels of 0,20, 40, 60 and $90 \mathrm{~s}$, respectively. We demonstrated that He RFP was more efficient against T. castaneum than Ar RFP. In addition, a positive correlation was observed between mortality percentages of treated insect stages and exposure times for both He and Ar RFP. The adult stage showed the highest tolerance to RFP irradiation followed by larvae and pupae; however, it was more susceptible than larvae within $24 \mathrm{~h}$ after He RFP treatments. The optimum exposure time was $90 \mathrm{~s}$ with He RFP, where a full mortality at all tested stages was accomplished, while mortalities of 71.4, 65.3 and $36.7 \%$ were recorded for pupae, larvae and adult stage, respectively, after an Ar RFP treatment of $90 \mathrm{~s}$. In case of treated adults, the reproduction rate was higher than treated larvae and pupae. Our findings indicated that He RFP was an effective method for inhibiting T. castaneum development and impacting the insect life cycle and could be considered a promising tool for pest control of stored food.
\end{abstract}

Keywords Non-thermal plasma $\cdot \mathrm{He}$ and Ar gases $\cdot$ Stored product pest $\cdot$ Mortality $\cdot$ Reproduction rate $\cdot$ Red flour beetle

\section{Key message}

- Radio frequency plasma (RFP) irradiation is a promising treatment against pest insects.

- Helium (He) as a precursor gas is more effective against T. castaneum than argon (Ar).

Communicated by Christos Athanassiou.

Birgit A. Rumpold

rumpold@tu-berlin.de

Waheed A. A. Sayed

waheed.sayed@eaea.org.eg

Reda S. Hassan

redahassan28812@yahoo.com

Thanaa M. Sileem

thanaasileem@yahoo.com

1 Biological Applications Department, Nuclear Research Center, Egyptian Atomic Energy Authority, Cairo, Egypt

2 Department Education for Sustainable Nutrition and Food Science, Technische Universität Berlin, Marchstr. 23, D-10587 Berlin, Germany
- Both He RFP and Ar RFP had toxic effects on larvae, pupae and adults of $T$. castaneum.

\section{Introduction}

The red flour beetle Tribolium castaneum (Herbst) is considered a destructive pest that attacks most of stored products and economic commodities (Hagstrum 2016). It is ubiquitous in many regions around the world (Sokoloff 1977). Chemical fumigants that have been extensively used against T. castaneum and other stored product pests, in particular in developing countries, have detrimental effects on the ecosystem and its fauna, in particular ozone layer and human health (Zettler and Arthur 2000). Due to these environmental and health concerns, several pest control technologies have been proposed as alternatives, such as heat treatment (Arbogast 1981), essential oils (Saroukolai et al. 2010), ozone (Xinyi et al. 2017) and microwaves (Lu et al. 2010). However, drawbacks of these alternative pest control methods against $T$. castaneum include loss of nutrients and deterioration of food quality, long treatment times, temperature requirements that limit applications and high costs (Sileem et al. 2017). Over 
the last few decades, ionizing radiation has been proposed to protect commodities and stored products against insect pests. It is a process, where infested stored products and commodities are irradiated in order to sterilize, kill or prevent development of insect pests (Hallman et al. 2010; Morrison 1989). Ionizing radiation is successfully and increasingly applied as a disinfestation treatment that is produced via the disintegration of radioactive atomic nuclei. Although it is a simple, robust and well-established technology, its sources are not readily available in many regions and might become more difficult to obtain in the future as well, because the irradiation sources are decaying over time. Accordingly, attempts to find more green and effective pest control strategies have focused on the application of sustainable energy sources against stored product pests. Electron beam has been suggested to be used as a source of radiation (Codex Alimentarius Commission 2003), but the high applied doses of electron beam irradiation required to kill targeted insects may have unacceptable effects on product quality. Recently, another form of radiation, cold or non-thermal plasma, has been suggested to combine properties/effects of irradiation treatment with a sustainable energy source-which is one of the major challenges in radiation processes (Kaur et al. 2020). Plasma, the fourth state of matter, is an ionized gas containing free electrons. Ionized gas is generated by the addition of energy such as intense radiation, radio frequencies, extreme heat or electrical energy (Eliezer and Eliezer 2001), resulting in a combination of charged and neutral particles such as electrons, ions, atoms and molecules (Amami et al. 2008). Depending on the process used to generate the plasma, the neutral particles, electrons and ions can have different temperatures (Chen 1984). Non-thermal plasmas are a mixture of cold ions and neutral $\left(<60{ }^{\circ} \mathrm{C}\right)$ and energetic electrons $(\approx 1 \mathrm{eV})$. They are generated by electric discharge in a gas at vacuum condition, lower pressure or atmospheric pressure (Niemira 2012; Thirumdas et al. 2015). Radio frequency cold atmospheric plasma is generated by circulating radio frequency currents in antennas or coils, applying a radio frequency voltage across two parallel electrodes and immersed in the plasma by a dielectric window. Coupling of the electrons with electromagnetic fields facilitates energy that transferred them to sustain the plasma. The efficiency of the coupled power into the charged particles, as well as the plasma uniformity, is determined by the radio frequency excitation design (Chabert and Braithwaite 2011).

Many advantages are connected with non-thermal plasma irradiation such as low heat, short release time and relatively short process time. In addition, it involves few variables and has comparably low equipment costs. Therefore, atmospheric plasma operations have been extensively studied and its applications have gradually increased in various fields due to its appreciated economic efficiency (Tyata et al. 2012). In order to ensure its efficient adoption as a disinfestation treatment at industrial level as a safe and reliable alternative approach compared to ionizing radiation, significant research effort is still needed. It is difficult to optimize an optimal dose protocol against microorganisms and insect pests that infect food products where very varied equipment and operational environments have been used, resulting in very different plasma properties (López et al. 2019).

Recently, non-thermal plasma has been increasingly used in various industrial processes. It has been applied for medical applications such as sterilization, cancer treatment, wound healing and blood coagulation (Graves 2012). The effectiveness of non-thermal plasma as a technology for improving the shelf-life of food products by eliminating the microbial contamination from fresh and minimally processed food has been investigated, and it was observed that some species of Salmonella and bacterial spores were inactivated on dry food surfaces by non-thermal plasma (Fernández et al. 2012; Hertwig et al. 2018). It is also suggested as a promising method to protect dry food against stored product pest insects (Abd El-Aziz et al. 2014; Donohue et al. 2006; Keever et al. 2001; Mishenko et al. 2000; Mohammadi et al. 2015). The surface electrostatic excitation of membranes due to plasma may have a negative effect on nervous and neuromuscular systems of insects. This phenomenon may be attributable to the exposure to high voltage discharge and to the creation of anoxia, which may serve to anesthetize and immobilize insects (Bures et al. 2005; Donohue et al. 2006). Another effect of plasma on insects might be the breakdown of $\mathrm{C}-\mathrm{H}$ bonds in the lipid layer of the insect cuticle that causes dehydration of the insect and can lead to its death (Donohue et al. 2008).

Non-thermal plasma exhibits reactive oxygen species (ROS) which includes high reactive chemicals such as peroxides, superoxide, oxygen and hydroxyl radicals, and nitric oxide radicals (Ji et al. 2019) that have a negative impact on pest insects and may intensify the secondary metabolism of plant products that could maximize the economics of post-harvest treatment (Bußler et al. 2015; Laroussi and Leipold 2004). The effectiveness of plasma against microorganisms was determined by the type of gas used to generate the plasma and therefore responsible for free radical formation. It has been reported that cold plasma had no impact on the quality of dry stored products. Mortality-responses of $T$. castaneum were recorded at $2500 \mathrm{~V}$ for 1-5 min exposure times without significant changes in the color of the refined wheat flour (Mahendran et al. 2016). Furthermore, plasma treatment of wheat grains caused effective decontamination of bacteria and fungi together with insect pests and also enhanced the shelf life, germination and initial state of growth of the grains and resulted in an increased final grain yield. Moreover, the production of qualitatively better dough was also observed (Scholtz et al. 2019; Tyata et al. 2012). In 
this context, it was aimed to investigate the susceptibility of T. castaneum to radio frequency-induced cold atmospheric plasma (RFP) as an alternative pest control method with the following main objectives, (1) Confirm the efficacy of RFP as a killing method (2) Determine the sensitivity profile of different developmental stages exposed to different RFP doses using two different precursor gases. (3) Examine the mortality of irradiated $T$. castaneum where insect development was inhibited (4) Determine the reproduction rate resulting from RFP treated larvae and pupal stages.

\section{Materials and methods}

\section{Insects}

The red flour beetle. T. castaneum colony was maintained for several generations under controlled laboratory conditions of $27 \pm 2{ }^{\circ} \mathrm{C}$ and $70 \pm 2 \% \mathrm{RH}$ and continuous darkness. It was initially established from adults collected from infested storage wheat in Cairo governorate. The colony was fed on a rearing medium composed of wheat flour and brewer's yeast $(19: 1, w / w)$ (Ayvaz et al. 2002). The wheat flour was disinfested at $60{ }^{\circ} \mathrm{C}$ for $10 \mathrm{~h}$ to eliminate possible contaminants (Tunçbilek and Kansu 1996).

\section{Generation of radio frequency-induced cold atmospheric plasma (RFP) irradiation}

An RFP irradiation source was designed as shown in Fig. 1. It consisted of a generator of $13.65 \mathrm{MHz}$ radio frequency (RF) with an automatic tuner, a gas inlet, plasma chamber and a vacuum system. The RF antenna was fed 0-600 W.

Both the RF generator and the auto-matching network were from T\&C Power Conversion Inc, USA. Around the source chamber (Bottle), two coils allowed an on-axial magnetic field which provided 0-200 Gauss. This magnetic field confined the plasma electrons which increased the plasma

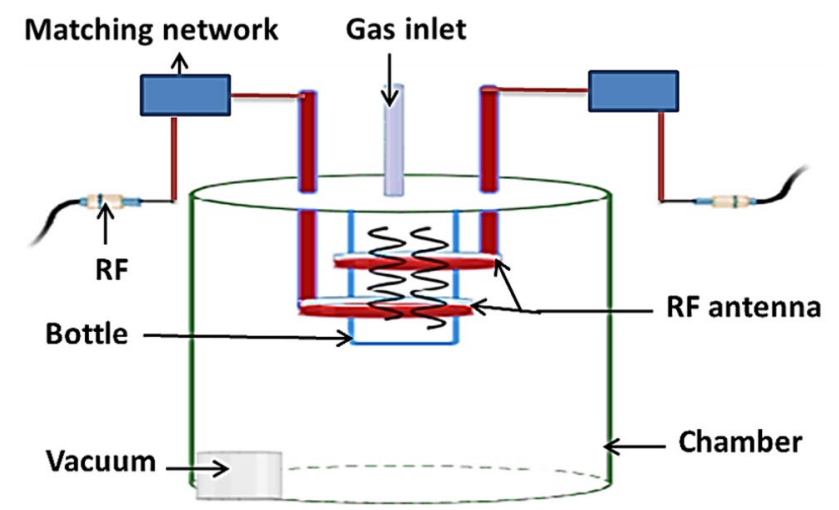

Fig. 1 Schematic diagram of a radio frequency plasma (RFP) source density. The sample holder was a Pyrex bottle $(250 \mathrm{ml})$ in which indirect plasma irradiation was performed in a batch system. A pressure of $150 \mathrm{kPa}$ was used. In the present experiment, helium (He) and argon (Ar) were utilized as precursor gases to create plasma, respectively.

\section{RFP treatment and subsequent bioassay of irradiated $T$. castaneum stages}

15- to 17-day-old larvae and one- to three-day-old pupae and 6- to 7-day-old adults were exposed to the plasma for 0 (control), 20, 40, 60 and $90 \mathrm{~s}$ at a power level of $100 \mathrm{~W}$ using helium and argon gases. For exposure, the larvae, pupae and adults were transferred separately into the Pyrex bottle, 30 larvae, 20 pupae and 30 adults, respectively, for each replicate. Three replicates were run for each dose (20, 40, 60 and $90 \mathrm{~s}$ ) and for the control groups ( $0 \mathrm{~s})$. The mortality of adults and larvae was recorded $6,12,18$ and $24 \mathrm{~h}$ after exposure to plasma. Pupal mortality was not recorded because the dead pupae could not be distinguished during these experimental times. The remaining plasma-treated larvae, pupae and adults were then maintained in the laboratory until death to observe their mortality or development of the treated larval and pupal stages to pupae and adults, respectively. The accumulative mortality was calculated at the end of adult survival as well as larval and pupal durations.

Remaining living adults per replicate that emerged from irradiated larvae and pupae, as well as treated adults, that had survived RFP treatments, were transferred using a fine brush to glass jars containing $20 \mathrm{~g}$ of rearing medium. These remaining adults were observed for survival and progeny as an indication of reproductive ability, where the reproduction rate of surviving adults, defined here as "the ability of adult previously irradiated as larvae and pupae as well as irradiated adults to produce progeny," was determined by placing those adult survivors on a rearing medium and counting the next generation ( $F_{1}$ progeny) produced at $43-44$ days. They are expressed as number of insects per $F_{1}$ progeny.

\section{Statistical analysis}

Data were analyzed using one way analysis of variance (ANOVA) technique and the means were analyzed using Duncan's multiple range test, the ANOVA statistics were significant $(p<0.01)$ (Steel and Torrie 1960). The data of mortality $(\%)$ were transformed by arcsine tables, while the means and standard errors of reproduction rate were from original data. The reproduction rate averages were calculated according to Aldryhim and Adam (1999) and Régnière et al. (2012), with the methodology described by Carey (1993) as follows: $\mathrm{R}=\mathrm{Ne} / \mathrm{Ns}$ where Ns is the number of adults at the beginning of generation ( $\mathrm{P} 1$ generation); $\mathrm{Ne}$ is the number of adults produced in the next generation ( $\mathrm{F} 1$ generation). 
The trendline labels were created by Excel 2010. The $\mathrm{Lt}_{50}$ values were estimated from the total mortality- response data (defined here as the lethal plasma exposure time to kill half the population) which were expressed as a percentage transformed using probit analysis (Abbott 1925) to allow for a direct comparison of insect mortality due to differences in susceptibility to the plasma discharge by different gases and different developmental stages of the insects exposed to the plasma for differing lengths of time.

\section{Results}

\section{Effect of RFP irradiation on T. castaneum stages}

Mortality of larval, pupal and adult stages of $T$. castaneum at the end of each developmental stage (accumulative mortality) after exposure to RFP are shown in Fig. 2. Results indicated that both Ar and He RFPs have a lethal effect on larval, pupal and adult stages. Significant mortalities of $1.2 \pm 0.00$, $11.4 \pm 0.00,18.7 \pm 0.00,43.3 \pm 0.02$ and $65.3 \pm 0.03 \%$ $\left(F_{4,10}=191.9, p>0.0005\right)$ were obtained in the case of $\mathrm{Ar}$ RFP treated larvae, mortalities of $3.2 \pm 1.59,35.1 \pm 1.92$, $38.5 \pm 0.28,48.3 \pm 1.88$ and $71.4 \pm 1.33 \%\left(F_{4,10}=35.9\right.$, $p>0.0005)$ for pupae and mortalities of $4.1 \pm 0.0,8.9 \pm 1.20$, $11.1 \pm 1.01,33.3 \pm 1.05$ and $36.7 \pm 1.45 \%\left(F_{4,10}=48.2\right.$, $p>0.0005$ ) for adults at $0,20,40,60$ and $90 \mathrm{~s}$, respectively. Significant mortalities of $3.7 \pm 0.00,18.4 \pm 0.02,39.5 \pm 0.05$, $73.8 \pm 0.04$ and $100 \%\left(F_{4,10}=1241.3, p>0.0005\right)$ were also observed for He RFP treated larvae, mortalities of $6.8 \pm 1.59$, $47.7 \pm 0.33,47.8 \pm 0.72,89.1 \pm 0.60$ and $100 \%\left(F_{4,10}=197.5\right.$, $p>0.0005)$ for pupae and mortalities of $0,10.2 \pm 0.33$,

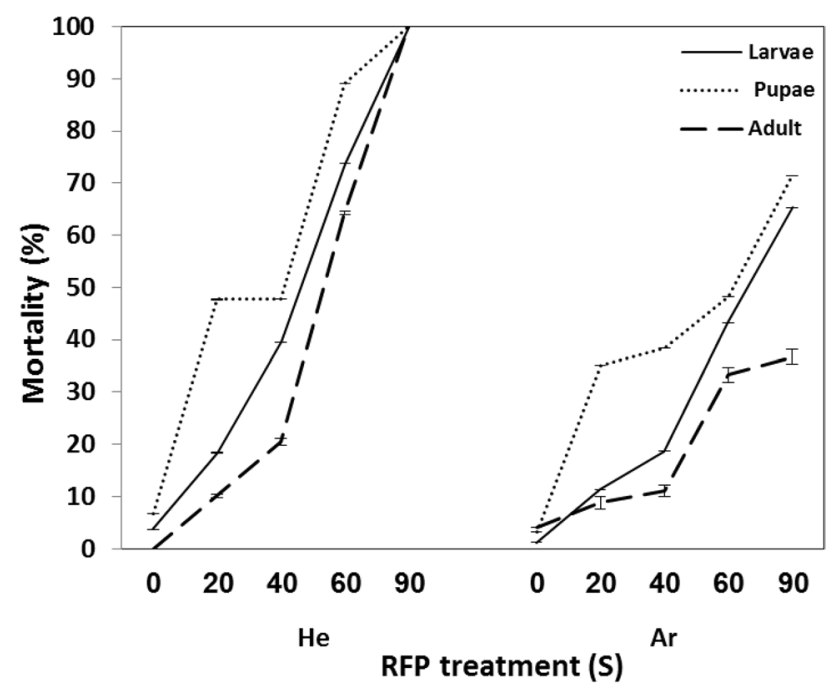

Fig. 2 Motality of the larval, pupal and adult stages exposed to different exposure times of RFP using Ar and He gases at the end of each developmental stage
$20.5 \pm 0.66,64.4 \pm 0.33$ and $100 \%\left(F_{4,10}=191.9, p>0.0005\right)$ for adults, respectively. The results indicated that the mortalities increased with increasing treatment time for both gases. Moreover, it was observed that He RFP was more effective than Ar RFP, where full mortality was obtained for larvae, pupae and adults after $90 \mathrm{~s}$ with He RFP, while relative mortalities were recorded in these stages at the same exposure times treated with Ar RFP.

\section{Evaluation of the reproduction rates of insect stages irradiated with RFP}

Figures 3 and 4 are depicting the effect of Ar and He RFP treatments, respectively, on the ability of irradiated larvae, pupae and adults to procreate a next generation compared to untreated insects as expressed by reproduction rates. The reproduction rates of larvae amounted to $4.4 \pm 0.5,3.4 \pm 0.3$, $1.6 \pm 0.17$ and $1.2 \pm 0.16\left(F_{4,10}=10.9 ; p=0.0013\right)$ upon $\mathrm{Ar}$ RFP treatment and $3.7 \pm 0.76,2.9 \pm 0.65,1.6 \pm 0.57$ and $0.0\left(F_{4,10}=19.9 ; p=0.0001\right)$ upon He RFP treatment for 20, 40, 60 and $90 \mathrm{~s}$, respectively. They were significantly reduced in comparison with the larvae reproduction rate of the control treatment (5.1). Similarly, the reduction of the reproduction rate was significant when the adult stage was treated with He RFP $(7.5 \pm 0.60,4.4 \pm 0.58,4.1 \pm 0.10$ and $\left.0.0 ; F_{4,10}=27.4, p<0.0005\right)$ and Ar RFP $(4.9 \pm 0.34$, $4.9 \pm 0.05,4.3 \pm 0.63$ and $3.4 \pm 0.10 ; F_{4,10}=10.8 ; p=0.0012$ ) for 20, 40, 60 and $90 \mathrm{~s}$, respectively, as compared to control treatment (8.8). Moreover, the reproduction rate was significantly decreased in pupae treated with $\operatorname{He} \operatorname{RFP}(3.1 \pm 0.10$,

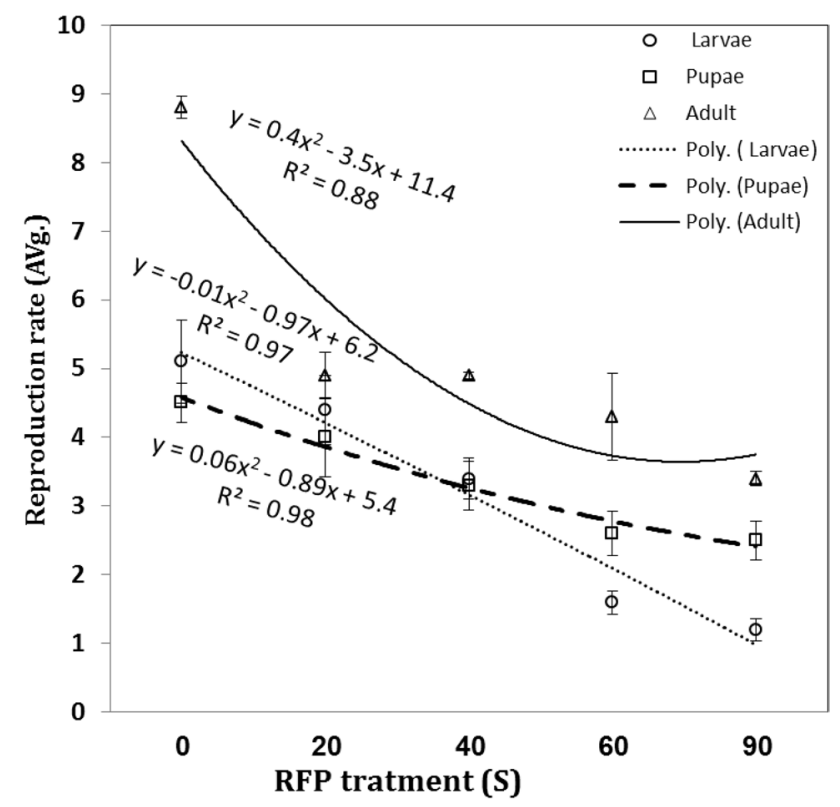

Fig. 3 Reproduction rates (Avg.) of larval, pupae and adult stages treated to different exposure times of RFP using Ar gas 


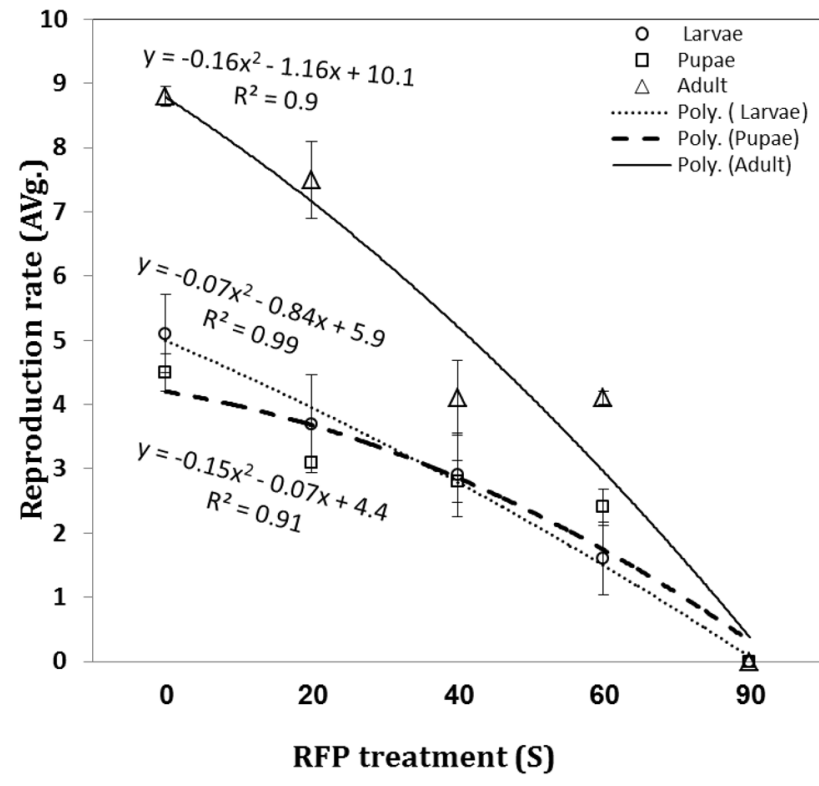

Fig. 4 Reproduction rates (Avg.) of larval, pupae and adult stages treated with different exposure times of RFP using He gas

$2.8 \pm 0.33,2.4 \pm 0.29$ and $\left.0.0 ; F_{4,10}=10.6, p=0.0032\right)$ and was also decreased for Ar RFP $(4 \pm 0.57,3.3 \pm 0.35$, $2.6 \pm 0.32$ and $2.5 \pm 0.28 ; F_{4,10}=5.2, p=0.0153$ ) for 20,40 , 60 and $90 \mathrm{~s}$, respectively, as compared to the control treatment $(4.5 \pm 0.29)$. The results indicated that the reproduction rates of treated adults were the highest in comparison with treated larvae and pupae for both Ar and He RFP treatments. Moreover, for Ar RFP, the reproduction rates of treated larvae were higher than for pupae at 20 and $40 \mathrm{~s}$, while the rates were higher in case of treated pupae than larvae at 60 and $90 \mathrm{~s}$. Similarly, the reproduction rates were lower for treated pupae than for treated larvae at exposure times of 20 and $40 \mathrm{~s}$ with He RFP, while it was lower for He RFP treated larvae than pupae after $60 \mathrm{~s}$.

\section{Determination of the lethal exposure time (LT) of He RFP treatment on $T$. castaneum stages}

The median lethal exposure time $\left(\mathrm{Lt}_{50}\right)$ in linear trend was calculated to obtain clear information about the susceptibility of insect stages to He RFP (Fig. 5) $\mathrm{Lt}_{50}$ of pupae (26.3 s) was drastically lower than of larvae and adults (39.0 s and $53.8 \mathrm{~s}$ ), respectively. Results indicated that the pupal stage was susceptible by twofold compared to adults and by 1.5fold compared to larvae.

\section{Mortality assay of $T$. castaneum stages $24 \mathrm{~h}$ after He RFP treatments}

The stored product pest management efficiency depends on instantly getting rid of larvae and adults. In this context, the

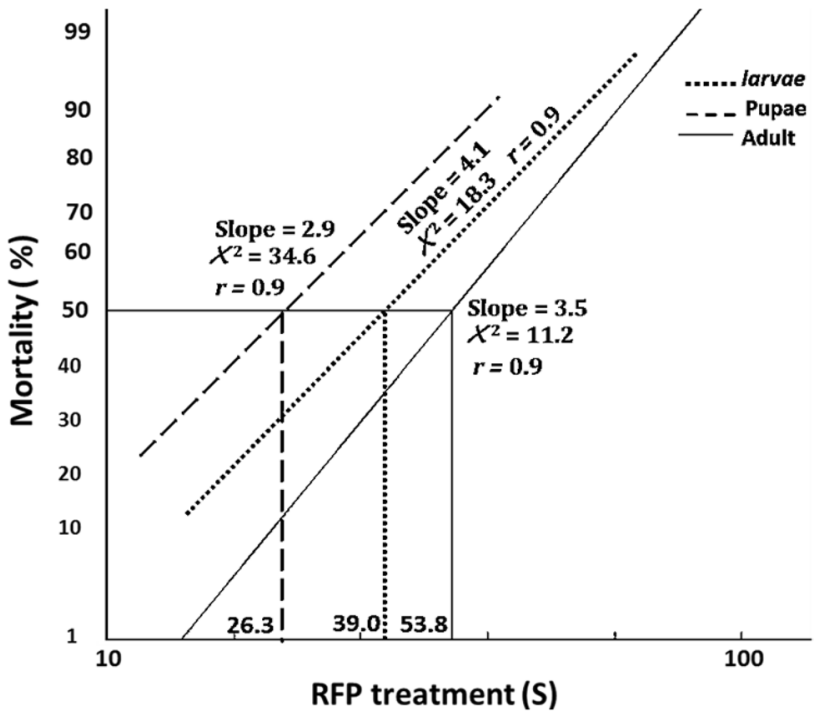

Fig. 5 LT50 of of larval, pupal and adult stages treated with He RFP for different exposure times of $0,20,40,60$ and $90 \mathrm{~s}$

mortality within $24 \mathrm{~h}$ upon He RFP treatment was determined (Fig. 6). It was observed that the mortality not only increased with increasing the exposure times of RFP but also varied with time up to $24 \mathrm{~h}$ after treatments. $6 \mathrm{~h}$ after treatment for $90 \mathrm{~s}$ with He RFP, intermediate mortalities of $42.3 \pm 1.17$ and $38.9 \pm 1.31 \%$ were observed for larvae and adults, respectively, while no lethal effects were recorded at exposure times of 20 and $40 \mathrm{~s}$ (Fig. 6a). This trend continued $12 \mathrm{~h}$ after RFP treatment, where the mortality was drastically increased to $96 \pm 2.08$ and $98 \pm 1.15 \%$ for larvae and adults, respectively, for $90 \mathrm{~s}$ treatment with He RFP as compared to mortalities of $11.2 \pm 0.91$ and $7.5 \pm 1.04 \%$ for $60 \mathrm{~s}$ (Fig. 6b). Also, high mortalities of $98.5 \pm 1.04$ and $100.0 \%$ were obtained $18 \mathrm{~h}$ after He RFP treatment of larvae and adults, respectively, for $90 \mathrm{~s}$ compared to mortalities of $25.0 \pm 1.76$ and $27.8 \pm 1.85 \%$ for $60 \mathrm{~s}$. In the same time frame (18 h after treatment), no mortality $(0 \%)$ was recorded for larvae treated for 20 and $40 \mathrm{~s}$, however, the mortality percentages were $8.4 \pm 0.64$ and $9.3 \pm 0.38 \%$ for treated adults, respectively (Fig. 6c). As shown in Fig. 6d, full mortality (100\%) was obtained for both larvae and adults treated for $90 \mathrm{~s} 24 \mathrm{~h}$ after treatments compared to mortalities of $53.4 \pm 0.65$ and $64.4 \pm 6.41 \%$ for larvae and adults, respectively, treated for $60 \mathrm{~s}$. In the same time frame $(24 \mathrm{~h}$ after treatment), the mortality of adults exposed for 20 and $40 \mathrm{~s}$ was $10.2 \pm 0.63$ and $20.5 \pm 0.63 \%$, respectively, while still no mortality was observed for the larval stage. These obtained data revealed that the mortality of the adult stage was higher than that of the larval stage of T. castaneum, both 18 and $24 \mathrm{~h}$ after plasma treatment. The obtained results for mortalities of $T$. castaneum larvae and adults within $24 \mathrm{~h}$ after treatment with He RFP indicated that adults were less 

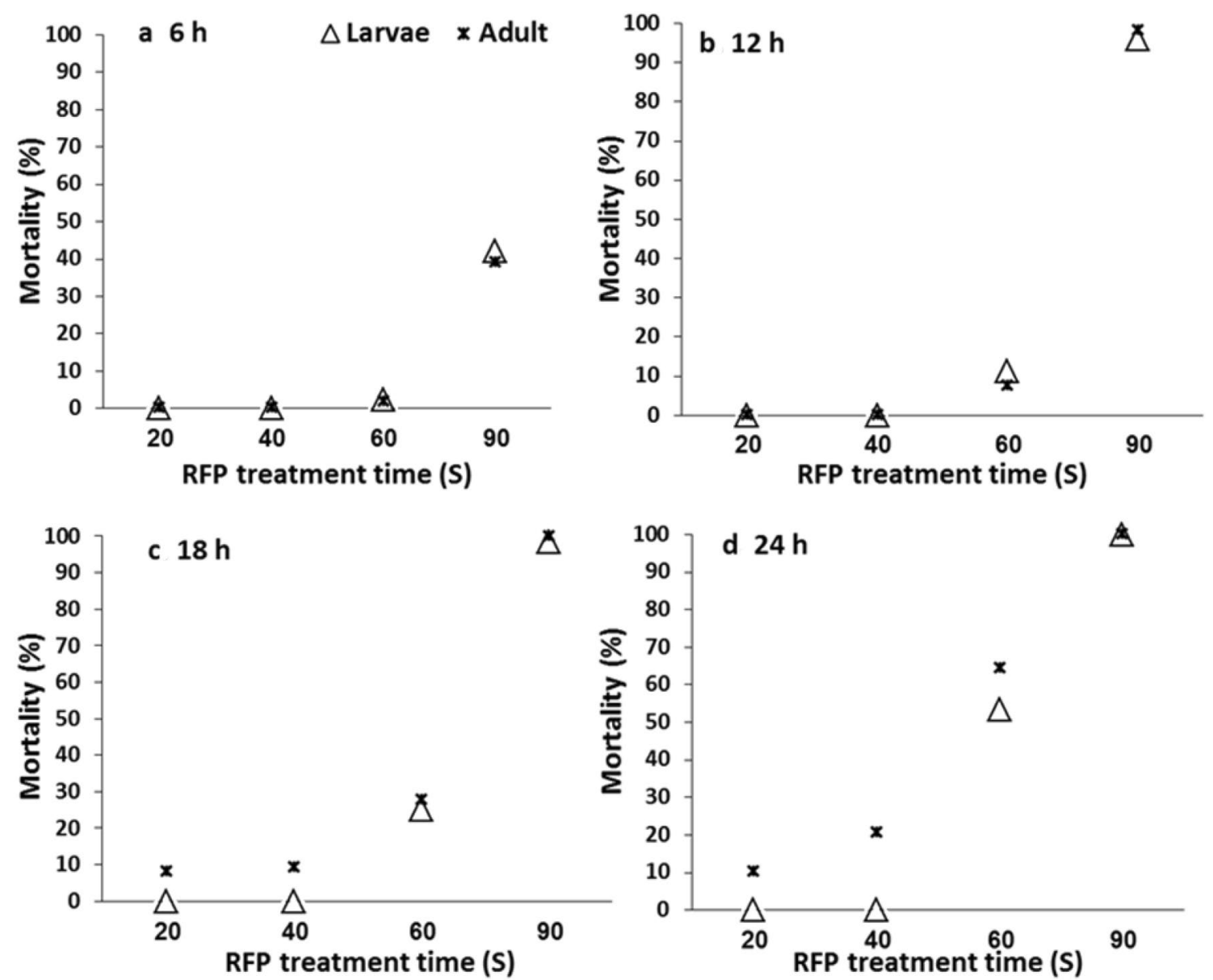

Fig. 6 Mortality percentages of larval, and adult stages of T. castaneum treated with He RFP for 20, 40, 60 and 90 s determined 6 (a), 12 (b), 18 (c), and 24 (d) hours after treatment

tolerant than larvae at sub-lethal doses (Fig. 6). These differences in tolerance within $24 \mathrm{~h}$ after treatment were converted in the accumulated mortality-responses that were recorded at the end of the larval duration and adult survival (Fig. 1).

\section{Discussion}

Results depicted in Fig. 2 are in accordance with other studies. For example, an inactivation of $T$. castaneum adults induced by Ar RFP was shown by Sileem et al. (2020) and also Carpen et al. (2019) who found a varied mortality induced by $\mathrm{Ar} /$ oxygen and $\mathrm{Ar} /$ nitrogen plasmas, where the nitrogen-containing plasma resulted in a higher mortality than argon/oxygen plasmas, while the He RFP was effective for the control of green peach aphids (Bures et al. 2005) and T. castaneum adults (Sileem et al. 2020). Evidently, plasma intensity and exposure times have different impacts on different insect stages and species. The power of $2500 \mathrm{~V}$ for $15 \mathrm{~min}$ at a $3.7 \mathrm{~cm}$ distance between electrodes induced full mortality of larvae and adult $T$. castaneum stages (Ramanan et al. 2018). Abd El-Aziz et al. (2014) found that a decrease in the distance of the plasma jet electrodes to the sample and increasing pulse numbers lead to increased mortality of $P$. interpunctella pupae. Nevertheless, at the maximum number of pulses and minimum distance, a larvae mortality of $86 \%$ was not exceeded. The impact of non-thermal plasma on Blattella germanica has been investigated by Donohue et al. (2008). They observed slightly opened wings, flaccid antennae, twitched legs and broken abdomen at high plasma doses, while lower doses caused limited responses such as lack of normal movement of treated insects. Malformation of $T$. castaneum larvae and partial and whole internal melanization of hemolymph has also been reported due to nonthermal plasma treatment (Ramanan et al. 2018). It was also suggested that the oxidative stress of plasma may damage the larval cuticle and epidermis and attract hemocytes to the affected area resulted from damage signals. The insect defense response by disintegration of fat bodies to heal the damage might cause the clotting and melanization. Similar responses were observed by Ferreira et al. (2016) on $D$. melanogaster larvae who reported that the effect of plasma 
on larval death might be extreme oxidative stress due to ROS, as well as the melanization caused by the activation of the immune system.

The various responses to radiation treatment of $T$. castaneum stages observed in our study were also obtained by Tunçbilek et al. (2003) in response to gamma rays, who found that the larvae were more susceptible than the adult stage. Also, Sileem et al. (2017) observed that the adult stage of Oryzaephilus surinamensis exposed to low doses of gamma radiation resulted in less sterility than those previously irradiated as larvae, while the irradiated pupae showed the highest sterility. The same trend was recorded by Aldryhim and Adam (1999) who found that the adults of Sitophilus granarius previously treated as pupae with cold plasma had a lower reproduction rate than the adults originating from treated larvae.

Comparing data after Ar and He RFP treatments revealed that there are differences in the reproduction rates of treated adults and also the adults that produced from treated larvae and pupae. Our results indicated that a reduction of the reproduction of treated insects with sub-lethal doses may be due to physiological changes in particular DNA damage due to the impact of active ingredients created by plasma such as ROS and charged particles and could be referred as indirect effect of plasma treatment. These differences of reproduction rates might due to differences in reactive species of $\mathrm{He}$ and Ar plasmas. For example, Kwon et al. (2019) found a different distribution of different ROS in two atmospheric plasmas. However, they could not confirm the role of ROS that resulted in insect death after plasma treatments. Furthermore, Kawasaki et al. (2015) found that the ROS amount varied depending on the equipment used for plasma generation. It was observed that in case of cold plasma treatments of $T$. castaneum, the differences of applied voltage, electrode distances and exposure time caused differences in mortality (Mahendran et al. 2016). The insect mortality, reproduction rate and insect sterility after ionizing radiation treatments have been investigated (Hallman et al. 2010). These responses were attributed to the direct effect of ionizing radiation on DNA and their indirect effect due to released free radicals attacking DNA chains (Hutchinson 1985). These effects on DNA were also investigated with UV radiation (Ravanat et al. 2001) and non-ionizing electromagnetic fields (Saliev et al. 2019). In this context, the mechanism of cold plasma which creates many active ingredients may contribute to DNA damage of insect cells. More research will be required to examine whether non-thermal plasma is inducing this damage. Our results presented a reduction of $F_{1}$ generation (reproduction rate), which indicates latent effects of plasma on treated insect expressed as negative impact on insect fertility rather than direct mortality. This effect may be attributed to the reactive species in particular the reactive oxygen species (ROS) mediated by plasma that cause indirect effects on DNA, immune system and circulatory system of insects. This hypothesis is going in line with the impact of ROS produced by chemical treatment (Kumar et al. 2015), thermal treatment (Lubawy et al. 2019) and low doses of gamma radiation (Zhikrevetskaya et al. 2015) on DNA damage of $P$. interpunctella, Gromphadorinha coquereliana and Drosophila melanogaster, respectively. Another possible explanation is the direct impact of plasma on the nervous system (Donohue et al. 2006). Moreover, in order to maintain homeostasis, the antioxidant enzymes of the defense system were significantly changed in P. interpunctella exposed to non-thermal plasma due to the free radicals (Abd El-Aziz et al. 2014). However, to confirm these mechanisms further, biochemical and molecular genetic studies are needed.

Our results regarding lethal exposure times are contradictory to Keever et al. (2001) who suggested that pupal and adult stages were more tolerant to plasma because they have a hard exterior and puparium for protection against plasma radiation. Their statement only refers to the direct effect of plasma radiation that was thought to be effective only at the target's surface, but this hypothesis does not take into account the indirect effect due to ROS. It has been shown that ROS of cold plasma can penetrate into deeper layers of model bacteria biofilms resulting in DNA damage (Govaert et al. 2020). This finding supports our hypothesis of inflicted damage via plasma penetration of pupal cells similar to the penetration through meat and crevices and cracks of seeds (Misra et al. 2019). This indirect effect of ROS could explain the finding by Nasr et al. (2020) who recorded that the adults of T. castaneum and Sitophilus granaries were the most susceptible to direct cold plasma treatments of up to $25 \mathrm{~min}$. Although these results contradict our findings, their study on the tolerance of larval and pupal stages goes in line with the results of our study.

It is clear that the adult stage was more susceptible for the direct effect of RFP that was visible within $24 \mathrm{~h}$ after treatment than the larval stage, while it was more tolerant than the larval stage to the indirect effect of RFP caused by reactive species that could cause free radicals with oxidizing effects in treated insect cells. These radicals attack the cell molecules, which may have time-delayed lethal effects on the insect after the plasma treatment. This effect has been demonstrated in case of gamma radiation treatments which caused different mortality-responses during the life span of treated insects. However, it was observed that the capacity of total antioxidants of Drosophila melanogaster stages was nearly constant (Paithankar et al. 2017). Oxidizing effects in $P$. interpunctella larvae treated by cold plasma have been reported that caused a significant reduction of protein and glutathione contents, as well as high levels of lipid peroxide. In comparison with the other insect stages, the plasma treatment resulted in a high sensitive reaction of the larval stage 
(Abd El-Aziz et al. 2014). The response of larvae, pupae and adults to that time-delayed effect of plasma treatment will be different by its variance in the intrinsic physiological characteristics and the immunity system. To confirm our hypothesis, further biochemical and molecular research is required to identify the repair enzymes involved in the different insect stages in relation to the induced DNA damage.

\section{Conclusion}

Radio frequency-induced cold atmospheric plasma (RFP) can be considered a promising alternative for irradiation processes against pest insects. The sensitivity of $T$. castaneum to the two types He and Ar RFP was investigated and compared. He RFP is more effective in inactivating T. castaneum at all three developmental stage than Ar RFP. However, both $\mathrm{He}$ and Ar had a toxic effect on larvae, pupae and adults. The mortality gradually increased with increasing exposure time for both types of plasma. Moreover, both types Ar and He RFP had latent effects on insect stages, where they were effective in reducing the reproduction rate of treated adults and the adults produced from treated larvae and pupae. The optimum exposure time of RFP for preventing development and procreation was $90 \mathrm{~s}$ applying He RFP. The susceptibility of insect stages to He RFP treatment differed. The pupal stage was the most susceptible followed by larval and adult stages. However, the adult stage was more susceptible than larvae within $24 \mathrm{~h}$ after treatments. Our results indicated that RFP could successfully be used for managing the T. castaneum pest due to both toxic and latent effects. But further research is required to evaluate the ability of non-thermal plasma to penetrate the various food products for using as a phytosanitary treatment rather than surface treatment. In addition, the effects of cold plasma treatments on insects and their fertility need to be studied in more detail on a molecular and a species-specific level in order to design targeted plasma treatments with the desired effects on specific insects while conserving the stored goods. Research is also required on plasma treatment of infested food under typical storage conditions and volumes. Treatment conditions need to be determined where the respective treated food remains unaltered while the targeted pest insects are inactivated. In addition, upscaling and economic as well as environmental aspects need to be considered.

Acknowledgement The authors are grateful to assent Prof. Amin M. Hassan from Accelerators and Ion Sources Department, Nuclear Research Center, Atomic Energy Authority, for providing the necessary laboratory facilities and assistance in designing the irradiation protocol.

Authors' contributions WAS, TMS and RSH conceived and designed research. TMS and RSH conducted experiments. WAS, TMS and RSH analyzed data. WAS and BAR wrote the manuscript. All authors read and approved the manuscript.

Funding Open Access funding enabled and organized by Projekt DEAL.. This research did not receive any specific grant from funding agencies in the public, commercial or not-for-profit sectors.

\section{Compliance with ethical standards}

Conflicts of interest The authors declare that they have no conflict of interest.

Ethics approval This article does not contain any studies with human participants or vertebrates performed by any of the authors.

Open Access This article is licensed under a Creative Commons Attribution 4.0 International License, which permits use, sharing, adaptation, distribution and reproduction in any medium or format, as long as you give appropriate credit to the original author(s) and the source, provide a link to the Creative Commons licence, and indicate if changes were made. The images or other third party material in this article are included in the article's Creative Commons licence, unless indicated otherwise in a credit line to the material. If material is not included in the article's Creative Commons licence and your intended use is not permitted by statutory regulation or exceeds the permitted use, you will need to obtain permission directly from the copyright holder. To view a copy of this licence, visit http://creativecommons.org/licenses/by/4.0/.

\section{References}

Abbott WS (1925) A method of computing the effectiveness of an insecticide. J Econ Entomol 18:265-267. https://doi.org/10.1093/ jee/18.2.265a

Abd El-Aziz MF, Mahmoud EA, Elaragi GM (2014) Non thermal plasma for control of the Indian meal moth, Plodia interpunctella (Lepidoptera: Pyralidae). J Stored Prod Res 59:215-221. https:// doi.org/10.1016/j.jspr.2014.03.002

Aldryhim YN, Adam EE (1999) Efficacy of gamma irradiation against Sitophilus granarius (L.) (Coleoptera: Curculionidae). J Stored Prod Res 35:225-232. https://doi.org/10.1016/S0022-474X(99) 00007-7

Amami E, Khezami L, Vorobiev E, Kechaou N (2008) Effect of pulsed electric field and osmotic dehydration pretreatment on the convective drying of carrot tissue. Dry Technol 26:231-238. https://doi. org/10.1080/07373930701537294

Ayvaz A, Ozturk F, Yaray K, Karahacio E (2002) Effects of the gamma radiations and malathion on confused flour beetle Tribolium confusum. J Val Pak J Biol Sci 5:560-562. https://doi.org/10.3923/ pjbs.2002.560.562

Bures BL, Donohue KV, Roe RM, Bourham MA (2005) Visualization of helium dielectric barrier discharge treatment of green peach aphids on tobacco leaves. IEEE Trans Plasma Sci 33:290-291. https://doi.org/10.1109/TPS.2005.845035

Bußler S, Herppich WB, Neugart S, Schreiner M, Ehlbeck J, Rohn S, Schlüter O (2015) Impact of cold atmospheric pressure plasma on physiology and flavonol glycoside profile of peas (Pisum sativum 'Salamanca'). Food Res Int 76:132-141. https://doi.org/10.1016/j. foodres.2015.03.045

Carey JR (1993) Applied demography for biologists with special emphasis in insects. Oxford University Press, New York, p 206 
Carpen L, Chireceanu C, Teodorescu M, Chiriloaie A, Teodoru A, Dinescu G (2019) The effect of argon/oxygen and argon/nitrogen atmospheric plasma jet on stored products pests. Rom J Phys 64:1-11

Chabert P, Braithwaite N (2011) Physics of radio-frequency plasmas. Cambridge University Press, Cambridge

Chen FF (1984) Introduction to plasma physics and controlled fusion: plasma physics, vol 1. Plenum Press, New York

Donohue KV, Bures BL, Bourham MA, Roe RM (2006) Mode of action of a novel nonchemical method of insect control: atmospheric pressure plasma discharge. J Econ Entomol 99:38-47. https://doi.org/10.1093/jee/99.1.38

Donohue KV, Bures BL, Bourham MA, Roe RM (2008) Effects of temperature and molecular oxygen on the use of atmospheric pressure plasma as a novel method for insect control. J Econ Entomol 101:302-308. https://doi.org/10.1603/0022-0493(2008)101[302: eotamo]2.0.co;2

Eliezer S, Eliezer Y (2001) The fourth state of matter: an introduction to plasma science, 2nd edn. Institute of Physics, Bristol

Fernández A, Shearer N, Wilson DR, Thompson A (2012) Effect of microbial loading on the efficiency of cold atmospheric gas plasma inactivation of Salmonella enterica serovar Typhimurium. Int J Food Microbiol 152:175-180. https://doi.org/10.1016/j.ijfoo dmicro.2011.02.038

Ferreira MI, Gomes JGL, Benilov MS, Khadem M (2016) Effects of nonthermal atmospheric-pressure plasma on drosophila development. Plasma Med 6:115-124. https://doi.org/10.1615/Plasm aMed.2016016768

Codex Alimentarius Commission (2003) General standard for irradiated foods: CODEX STAN 106-1983, REV.1-2003. Food and Agriculture Organization of the United Nations, Rome

Govaert M, Smet C, Walsh JL, Van Impe JF (2020) Influence of plasma characteristics on the inactivation mechanism of cold atmospheric plasma (CAP) for Listeria monocytogenes and Salmonella Typhimurium biofilms. Appl Sci 10(9):3198

Graves DB (2012) The emerging role of reactive oxygen and nitrogen species in redox biology and some implications for plasma applications to medicine and biology. J Phys D Appl Phys 45:263001. https://doi.org/10.1088/0022-3727/45/26/263001

Hagstrum D (2016) Fundamentals of stored-product entomology. Elsevier, Amsterdam

Hallman GJ, Levang-Brilz NM, Zettler JL, Winborne IC (2010) Factors affecting ionizing radiation phytosanitary treatments, and implications for research and generic treatments. J Econ Entomol 103:1950-1963. https://doi.org/10.1603/ec10228

Hertwig C, Meneses N, Mathys A (2018) Cold atmospheric pressure plasma and low energy electron beam as alternative nonthermal decontamination technologies for dry food surfaces: a review. Trends Food Sci Technol 77:131-142. https://doi.org/10.1016/j. tifs.2018.05.011

Hutchinson F (1985) Chemical changes induced in DNA by ionizing radiation. Prog Nucl Acid Res Mol Biol 32:115-154

Ji WO, Lee MH, Kim GH, Kim EH (2019) Quantitation of the ROS production in plasma and radiation treatments of biotargets. Sci Rep 9:1-11

Kaur M, Hüberli D, Bayliss KL (2020) Cold plasma: exploring a new option for management of postharvest fungal pathogens, mycotoxins and insect pests in Australian stored cereal grain. Crop Pasture Sci 71:715-724. https://doi.org/10.1071/CP20078

Kawasaki T, Eto W, Hamada M, Wakabayashi Y, Abe Y, Kihara K (2015) Detection of reactive oxygen species supplied into the water bottom by atmospheric non-thermal plasma jet using iodinestarch reaction. J Phys D Appl Phys 54:86201. https://doi.org/10. 7567/JJAP.54.086201

Keever DW, Dowdy AK, Bures BL, Hankins OE, Bourham MA (2001) Mortality and sterility of the cigarette beetle, Lasioderma serricorne (F.), due to exposure to atmospheric plasma. In: MBAO (ed) Proceedings of the 2001 annual international research conference on methyl bromide alternatives and emissions reductions

Kumar S, Park J, Kim E, Na J, Chun YS, Kwon H, Kim W, Kim Y (2015) Oxidative stress induced by chlorine dioxide as an insecticidal factor to the Indian meal moth, Plodia interpunctella. Pestic Biochem Physiol 124:48-59. https://doi.org/10.1016/j.pestbp. 2015.04.003

Kwon DH, Kim H-S, Park M-R (2019) Plasma-based organism evaluation equipment using atmospheric-pressure plasma jets: efficacy for controlling insect pests. J Asia Pacific Entomol 22:868-873. https://doi.org/10.1016/j.aspen.2019.06.011

López M, Calvo T, Prieto M, Múgica-Vidal R, Muro-Fraguas I, AlbaElías F, Alvarez-Ordóñez A (2019) A review on non-thermal atmospheric plasma for food preservation: mode of action, determinants of effectiveness, and applications. Front Microbiol 10:622. https://doi.org/10.3389/fmicb.2019.00622

Lu H, Zhou J, Xiong S, Zhao S (2010) Effects of low-intensity microwave radiation on Tribolium castaneum physiological and biochemical characteristics and survival. J Insect Physiol 56:13561361. https://doi.org/10.1016/j.jinsphys.2010.04.019

Lubawy J, Daburon V, Chowański S, Słocińska M, Colinet H (2019) Thermal stress causes DNA damage and mortality in a tropical insect. J Exp Biol. https://doi.org/10.1242/jeb.213744

Mahendran R, Ramanan KR, Ravichandran S, Sarumathi R (2016) Effect of cold plasma on mortality of Tribolium Castaneum on maida flour. Sci J Agric Eng XLI:37-44

Mishenko AA, Malinin OA, Rashkovan VM, Basteev AV, Bazyma LA, Mazalov Y, Kutovoy VA (2000) Complex high-frequency technology for protection of grain against pests. J Microw Power Electromagn Energy 35:179-184. https://doi.org/10.1080/08327 823.2000 .11688435

Misra NN, Yepez X, Xu L, Keener K (2019) In-package cold plasma technologies. J Food Eng 244:21-31. https://doi.org/10.1016/j. jfoodeng.2018.09.019

Mohammadi S, Imani S, Dorranian D, Tirgari S, Shojaee M (2015) The effect of non-thermal plasma to control of stored product pests and changes in some characters of wheat materials. J Biodiv Environ Sci (JBES) 7:150-156

Morrison RM (1989) An economic analysis of electron accelerators and cobalt-60 for irradiating food (No. 1762-1765). US Department of Agriculture, Economic Research Service.]

Nasr MEH, Zinhoum RA, Lotfy K (2020) Efficacy of cold plasma against three of stored grain insects. Int J Entomol Res 5:113-117

Niemira BA (2012) Cold plasma decontamination of foods. Annu Rev Food Sci Technol 3:125-142. https://doi.org/10.1146/annur ev-food-022811-101132

Paithankar JG, Deeksha K, Patil RK (2017) Gamma radiation tolerance in different life stages of the fruit fly Drosophila melanogaster. Int J Radiat Biol 93:440-448. https://doi.org/10.1080/09553002. 2016.1266056

Ramanan RK, Sarumathi R, Mahendran R (2018) Influence of cold plasma on mortality rate of different life stages of Tribolium castaneum on refined wheat flour. J Stored Prod Res 77:126-134. https://doi.org/10.1016/j.jspr.2018.04.006

Ravanat JL, Douki T, Cadet J (2001) Direct and indirect effects of UV radiation on DNA and its components. J Photochem Photobiol B Biol 63(1-3):88-102

Régnière J, Powell J, Bentz B, Nealis V (2012) Effects of temperature on development, survival and reproduction of insects: experimental design, data analysis and modeling. J Insect Physiol 58:634647. https://doi.org/10.1016/j.jinsphys.2012.01.010

Saliev T, Begimbetova D, Masoud AR, Matkarimov B (2019) Biological effects of non-ionizing electromagnetic fields: two sides of a coin. Prog Biophys Mol Biol 141:25-36 
Scholtz V, Šerá B, Khun J, Šerý M, Julák J (2019) Effects of nonthermal plasma on wheat grains and products. J Food Qual 2019:1-10. https://doi.org/10.1155/2019/7917825

Sileem TM, Hassan RS, Sayed WAA (2017) Increasing the control efficiency of sawtoothed grain beetle, Oryzaephilus surinamensis (L.) using gamma irradiation and some essential plant oils. Arab J Nucl Sci Appl 50:147-157

Sileem TM, Hassan RS, Mahmoud EA (2020) Adulticidal activity of atmospheric plasma irradiation against the red flour beetle, Tribolium castaneum. Int J Trop Insect Sci 40:645-650. https://doi. org/10.1007/s42690-020-00115-w

Sokoloff A (1977) The biology of Tribolium with special emphasis on genetic aspects, vol 3. Clarendon Press, Oxford

Thirumdas R, Sarangapani C, Annapure US (2015) Cold plasma: a novel non-thermal technology for food processing. Food Biophys 10:1-11. https://doi.org/10.1007/s11483-014-9382-z

Tunçbilek AŞ, Kansu IA (1996) The influence of rearing medium on the irradiation sensitivity of eggs and larvae of the flour beetle, Tribolium confusum. J Val J Stored Prod Res 32:1-6. https://doi. org/10.1016/0022-474X(95)00039-A

Tunçbilek AS, Ayvaz A, Öztürk F, Kaplan B (2003) Gamma radiation sensitivity of larvae and adults of the red flour beetle, Tribolium castaneum Herbst. Anzeiger für Schädlingskunde (J Pest Sci) 76:129-132. https://doi.org/10.1007/s10340-003-0002-9

Tyata RB, Subedi DP, Shrestha A, Baral D (2012) Development of atmospheric pressure plasma jet in air. Kathmandu Univ J Sci Eng Technol 8:15-22. https://doi.org/10.3126/kuset.v8i1.6035

Xinyi E, Subramanyam B, Li B (2017) Efficacy of ozone against phosphine susceptible and resistant strains of four stored-product insect species. Insects. https://doi.org/10.3390/insects8020042

Zettler JL, Arthur FH (2000) Chemical control of stored product insects with fumigants and residual treatments. Crop Prot 19:577-582. https://doi.org/10.1016/S0261-2194(00)00075-2

Zhikrevetskaya S, Peregudova D, Danilov A, Plyusnina E, Krasnov G, Dmitriev A, Moskalev A (2015) Effect of low doses (5-40 cGy) of gamma-irradiation on lifespan and stress-related genes expression profile in Drosophila melanogaster. PLoS ONE 10(8):e0133840

Publisher's Note Springer Nature remains neutral with regard to jurisdictional claims in published maps and institutional affiliations. 